\title{
The Usefulness of Preoperative Colonoscopic Tattooing with Autologous Blood for Localization in Laparoscopic Colorectal Surgery
}

\author{
Ui Do Yeo, M.D., Nak Song Sung, M.D., Seung Jae Roh, M.D., Won Jun Choi, M.D., Kyung Ho Song, M.D., In Seok Choi, M.D., \\ Dae Sung Yoon, M.D., Sang Eok Lee, M.D., Ph.D., Ju Ik Moon, M.D., Seong Uk Kwon, M.D., In Eui Bae, M.D., Seung Jae Lee, M.D. \\ Konyang University Myung-Gok Medical Research Institute and Department of Colorectal Surgery, Konyang University Hospital, Daejeon, Korea
}

Purpose: In colorectal cancer surgery, it is important to have accurate resection margins. However, it is challenging to localize lesions during laparoscopy. Therefore, to reduce surgical errors, many preoperative localizing methods have been introduced. In this study, we aimed to assess the preoperative feasibility and safety of autologous blood tattooing.

Methods: A total of 11 patients underwent preoperative colonoscopic autologous blood tattooing from August 2017 to February 2020. At the start of the surgery, the surgeon assessed the patients for the precision of visibility and other complications such as abscess or spillage. The patients' characteristics, outcomes, and complications were collected retrospectively.

Results: The study comprised 8 men and 3 women, with an average age of 63 years. Ten patients showed precise visibility, and no localization errors were observed during surgery. No complication was observed in all patients.

Conclusion: Preoperative autologous blood tattooing is a very useful and safe technique because it has high visibility with no complications. This method does not require additional agents or facilities. A large-scale study will be required to develop standard guidelines.

Keywords: Colonoscopy, Tattooing, Localization, Autologous blood, Colorectal cancer

This is an Open Access article distributed under the terms of the Creative Commons Attribution Non-Commercial License (http:// creativecommons.org/licenses/by-nc/4.0/) which permits unrestricted non-commercial use, distribution, and reproduction in any medium, provided the original work is properly cited.
Received May 8, 2020

Revised July 18, 2020

Accepted August 11, 2020

Corresponding author Nak Song Sung Department of Surgery, Konyang University Hospital, 158 Gwanjeodong ro, Seo-gu, Daejeon 35365, Korea Tel: +82-42-600-8956 Fax: +82-42-543-8956 E-mail: kysns@kyuh.ac.kr ORCID:

https://orcid.org/0000-0002-7549-3829

\section{INTRODUCTION}

In colorectal cancer, laparoscopy has oncological results similar to that of open surgery, ${ }^{1,2}$ and this has led to a dramatic shift towards laparoscopic colorectal resection. ${ }^{3}$ However, lesions are difficult to identify through laparoscopy due to the increasing early detection rates of colon cancer due to regular health checkups. It makes the lesion getting smaller when it was first detected. Moreover, flat or small lesions are more difficult to detect outside the intestinal lumen of patients with early-stage cancer who underwent endoscopic mucosal resection (EMR) or endoscopic submucosal dissection.

To have sufficient resection margins, it is important to identify the tumor lesions before the surgery.

Surgeons apply a recognition method, either colonoscopy or sigmoidoscopy, to note the distance from the anus to the lesion, but this method is sometimes not accurate. ${ }^{4}$ Thus, many preoperative procedures have been designed, such as barium imaging, computed tomography (CT) combined with colonoscopy, reendoscopy, endoscopic clipping, and endoscopic tattooing using methylene blue and India ink. ${ }^{5-9}$

It is an advantage to find the lesions outside the intestinal lu- 

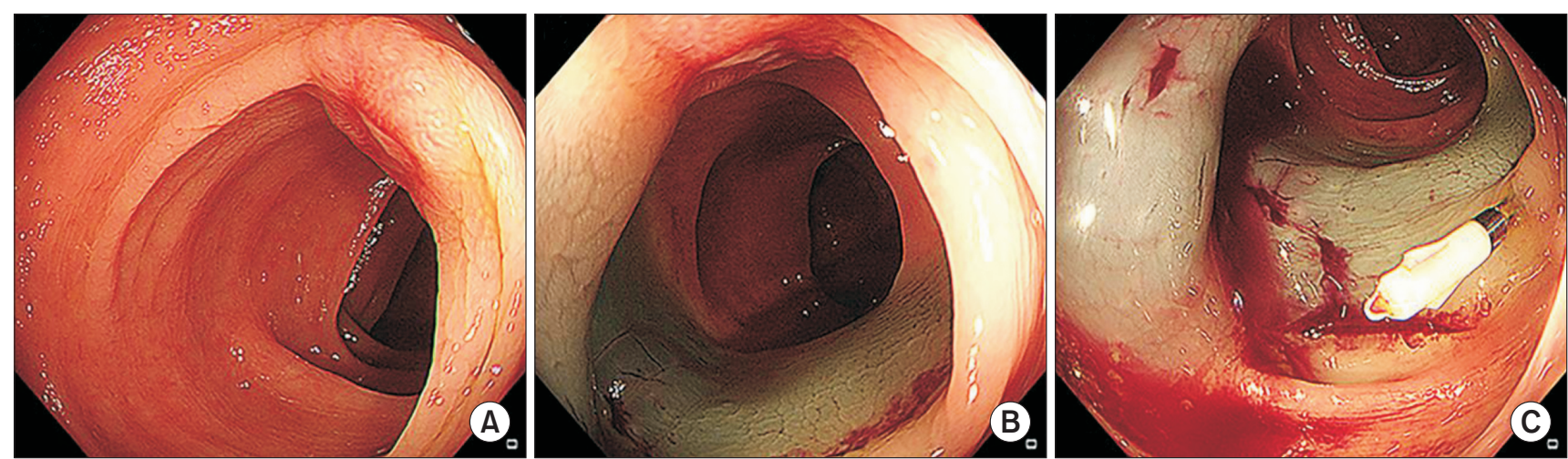

Fig. 1. Preoperative colonoscopic tattooing procedure with autologous blood. (A) Target lesion is observed in the colonoscopy. (B) Colonoscopic tattooing with autologous blood is performed. (C) Additional endoscopic clip is applied.

men, but there are also many known complications associated with the abovementioned methods. Preoperative endoscopic clipping could result in invisibility due to loss of clips, ${ }^{8,10}$ while preoperative tattooing, which uses tattooing agents such as methylene blue, India ink, and indocyanine green (ICG), lead to invisibility of the tattoo and complications caused by tattoo spillage. ${ }^{11-13}$ To minimize these adverse events, several studies performed tattooing with patient's own blood.

Therefore, this study aimed to evaluate the usefulness of a colonoscopic tattooing with autologous blood before surgery for localization in laparoscopic colorectal surgery.

\section{MATERIAL AND METHODS}

\section{Patients}

A total of 11 patients underwent preoperative localization with autologous blood tattooing prior to laparoscopic colorectal surgery from August 2017 to February 2020. Preoperatively, all patients underwent colonoscopy, abdominal and chest CT scans, basic blood testing, chest radiography, and electrocardiography, as well as mechanical bowel preparation before colonoscopic tattooing. Solid food was not allowed the day before colonoscopy and after lunch. Participants received a $4-\mathrm{L}$ dose of polyethylene glycol solution (CoLyte F powder, Taejoon Pharm, Seoul, Korea) before colonoscopy, 2-L dose the day before the endoscopy, and 2 -L dose during the endoscopy day in a split dose. All the patients underwent elective colon resection surgeries. Indications for colon rectal surgery included large lateral-spreading tumors that could not be treated endoscopically, malignant colorectal cancers, and endoscopically resected malignant polyps requiring additional colectomy. The exclusion criterion was the presence of mid-to-lower rectal cancer, because tattooing could not be visible under peritoneal reflection. The surgical outcomes and complications associated with endoscopic tattooing included abscess formation, perforation, post-tattoo fever, and peritonitis, which were evaluated by reviewing the patients' medical records retrospectively. This study was approved by the Institutional Review Board (IRB) (IRB No. KYUH 2020-04-001).

\section{Localization procedure}

Autologous blood tattooing was performed by two gastroenterologists with at least 10 years of experience, and all reports were recorded in the database. The tattooing was performed at least 72 hours before the surgery, and prophylactic antibiotics were not administered before tattooing in all patients. After identification of the lesion by endoscopy, the patient's blood was collected using a $10 \mathrm{ml}$ simple syringe without heparin preparation. After creating a normal saline bleb using a conventional endoscopic needle to avoid perforation or intraperitoneal spillage, 2 3 $\mathrm{ml}$ of self-blood was injected into each submucosa at 3 or 4 points circumferentially depending on the endoscopist, approximately the same level or just distal from the target lesion (Fig. 1). In total, 6 12 $\mathrm{ml}$ of autologous blood was used. In all patients, an endoscopic clip was applied under the assumption that the selfblood tattoo may not be visible. After colonoscopic tattooing, the patient's symptoms and vital signs were checked before surgery. While checking the intraperitoneal cavity at the start of the surgery, the tattooed site was first checked (Fig. 2), and a laparoscopic metal clip was applied to the same location. The surgeon recorded the degree of localization of the tattooing was divided into precise (localized and clearly visible), imprecise (not localized or not clearly visible), and undetected (not localized and not clearly visible) (Fig. 3). The spillage or abscess formation at the tattooed site during surgery was also checked. When necessary, intraoperative colonoscopy was attempted during surgery in case of inaccurate or undetected localization. 

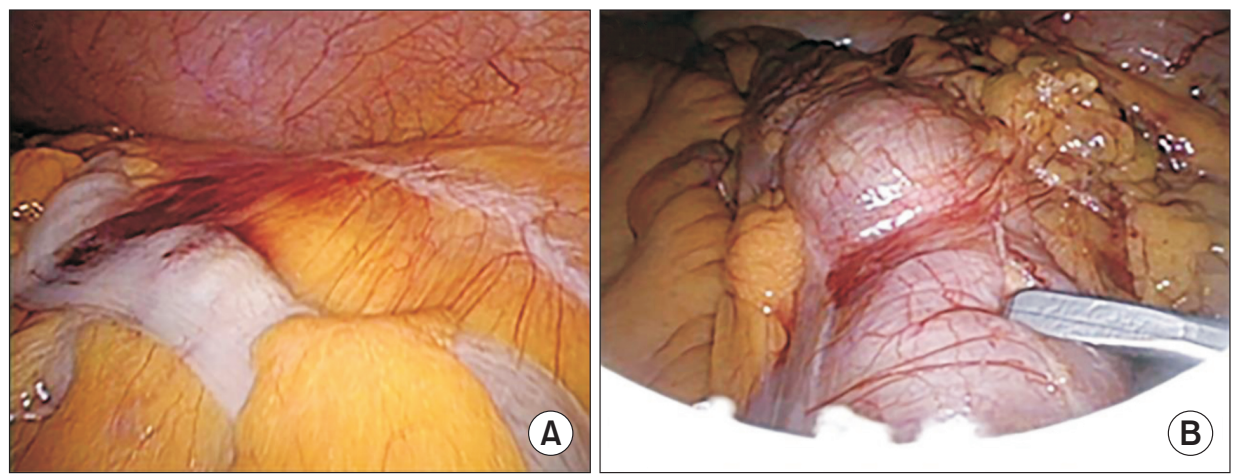

Fig. 2. Laparoscopic view of an autologous blood tattooed colon. (A) Precise case in the descending colon. (B) Imprecise case in the hepatic flexure colon.
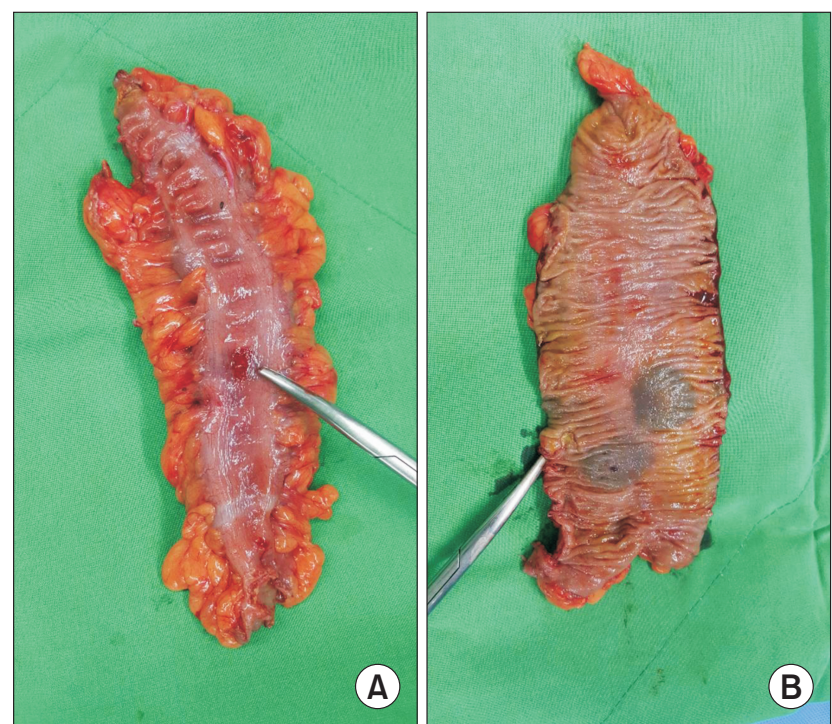

Fig. 3. Resected colon specimen localized with autologous blood tattooing (precise case). (A) Serosal view. (B) Mucosal view.

\section{RESULTS}

\section{Baseline characteristics}

Patients' characteristics are summarized in Table 1.

Eight men and three women were included in this study, and their mean age (min max age) was 62.9 years (50 78 years). All patients had an American Society of Anesthesiologists classification II, except for one, with ASA classification I. Six had a body mass index of $25 \mathrm{~kg} / \mathrm{m}^{2}$ or higher. Previous colectomy was performed in three patients who underwent low anterior and anterior resection due to rectal and sigmoid colon cancer and segmental colectomy due to sigmoid colon perforation. The tumor histological types were as follows: 3 adenomas, 6 adenocarcinomas, 1 neuroendocrine tumor, and 1 spindle cell tumor, of which 4 out of the 6 adenocarcinoma patients underwent EMR at an external hospital or our hospital, but surgery was performed due to tumor depth or a positive resection margin. Tattooing sites
Table 1. Patients' characteristics

\begin{tabular}{|c|c|}
\hline Variables & Patients ( $n=11)$ \\
\hline Mean age, year (min max) & $62.9(50 \sim 78)$ \\
\hline Gender, Male, n (\%) & $8(72.7)$ \\
\hline \multicolumn{2}{|l|}{ ASA classification, n (\%) } \\
\hline 1 & $1(9.1)$ \\
\hline$\|$ & $10(90.9)$ \\
\hline Obesity, ( $\geq 25$ kg/m²), n (\%) & $6(54.5)$ \\
\hline Previous colectomy, n (\%) & $3(27.3)$ \\
\hline \multicolumn{2}{|l|}{ Type of colorectal neoplasm, n (\%) } \\
\hline Adenoma & $3(27.3)$ \\
\hline Adenocarcinoma & $6(54.5)$ \\
\hline Neuroendocrine tumor & $1(9.1)$ \\
\hline Spindle cell tumor & $1(9.1)$ \\
\hline \multicolumn{2}{|l|}{ Location of tumor, n (\%) } \\
\hline Ascending colon & $2(18.2)$ \\
\hline Hepatic flexure colon & $2(18.2)$ \\
\hline Transverse colon & $0(0)$ \\
\hline Descending colon & $3(27.3)$ \\
\hline Splenic flexure colon & $1(9.1)$ \\
\hline Sigmoid colon & $3(27.3)$ \\
\hline Rectosigmoid & $0(0)$ \\
\hline $\begin{array}{l}\text { Median Interval between tattooing and } \\
\text { surgery (range), hours }\end{array}$ & $29.2(4 \sim 73)$ \\
\hline
\end{tabular}

ASA $=$ American Society of Anesthesiologist.

were observed in the following: 2 ascending colons, 2 hepatic flexure colons, 3 descending colons, and 3 sigmoid colons, but were not observed in the rectosigmoid or transverse colons. The average time from tattooing to surgery (min max hours) was 29.2 hours (4 73). 
Table 2. Clinical outcomes and complications

\begin{tabular}{lc}
\hline \multicolumn{1}{c}{ Variables } & Patients $(\mathrm{n}=11)$ \\
\hline Visibility rate, $\mathrm{n}(\%)$ & $10(90.9)$ \\
Precise & $10(90.9)$ \\
Imprecise & $1(9.1)$ \\
Undetected & $0(0)$ \\
Resection Margin, R0, $\mathrm{n}(\%)$ & $11(100)$ \\
Complications, $\mathrm{n}(\%)$ & $0(0)$ \\
Spillage & 0 \\
Abscess formation & 0 \\
Abdominal pain & 0 \\
Fever & 0 \\
Chill & 0 \\
\hline
\end{tabular}

\section{Clinical outcomes and complications}

Clinical outcomes and complication are summarized in Table 2. When the visibility of localization during surgery was confirmed among the 11 patients, 10 were precise and 1 was imprecise. The imprecise patient was tattooed on the hepatic flexure and the visibility was disturbed due to the greater omentum, although lesions were identified after omentectomy. After confirming the visibility during surgery, the surgical resection margin was negative in all the patients. After autologous blood tattooing, symptoms such as abdominal pain or chills before surgery and fever were not observed, and spillage or abscess at the tattooed site was also not identified during surgery.

\section{DISCUSSION}

In our retrospective study, we investigated the usefulness related to visibility and complication of autologous blood tattooing for lesion localization. Using this method, the visibility of the precise cases was $90.5 \%$, which was not inferior to that of other methods, and localization errors and complications were not observed in any of the patients. Additionally, since autologous blood tattooing is simple and practical, requiring no special tattooing agent or equipment, this method could be easily performed. ${ }^{14}$ In recent years, early detection rates of early colon cancer is gradually increasing, making the intraoperative identification of these lesions more difficult. ${ }^{12}$ Furthermore, in performing laparoscopic colon surgery, tumors are relatively limited in tactile feedback; hence, this localization is an important issue.

One of the preoperative localization methods is metal clipping and this method has a limitation in that the metal clips can be lost before the surgery. ${ }^{10}$ Also, intraoperative colon perforation has been reported in a case using magnetic clip. ${ }^{15} \mathrm{CT}$ colonograph and barium enema have also been used to determine the location of the lesion; however, if the tumor is small, endoscopic tattooing is needed. ${ }^{16}$ Various materials were tested during colonoscopic tattooing; India ink and ICG, methylene blue, hematoxylin and eosin, toluidine blue, and isosulfan blue were evaluated in animal experiments.

India ink is the most widely used material for tattooing, but it can cause inflammatory reactions like peritonitis due to colonic perforation or abscess. ${ }^{17-21}$ It contains foreign substances such as ethylene glycol, phenol, shellac, and gelatin. To reduce the inflammatory reaction, sterilization by on-site autoclaving (20 min at $110 \sim 121^{\circ} \mathrm{C}$ and $27.6 \mathrm{kPa}$ pressure) or by passage through a bacteriostatic Millipore filter $(0.22 \mu \mathrm{m})$ and subsequently dilution with normal saline solution are recommended. ${ }^{22}$ ICG which is mainly used for the evaluation of cardiac ejection ability and liver function, can also be used as a colon tattooing agent. ICG is relatively safer than India ink as a colon tattooing agent. ${ }^{23,24}$ However, indocyanine green is ineffective in that it tends to disappear within 3 7 days ${ }^{25,26}$ and it was reported that it induced colon ulcer in an animal study. ${ }^{25}$ The similar agent "Indocyanine green fluorance" persists until 7 days and has improved visibility, although it has a limitation in that it is visualized only with nearinfrared light. ${ }^{27}$

On the other hand, in the cases using self-blood tattooing methods, there were no known tattooing-related complications. Self-blood is remarkable in that it is not a foreign body like the other tattooing agents that cause inflammation in our body. There was one imprecise blood tattooed case. This was because of the location of the lesion, which was surrounded by the greater omentum and mesentery of colon. Therefore, we could identify only a small section of the blood-tattooed colon. We could avoid getting invisible cases by injecting $2 \sim 3 \mathrm{ml}$ of self-blood into each submucosa at 3 or 4 points circumferentially and referring other patients for the endoscopic auto blood tattooing method, which requires 4 points " 1 " $\mathrm{ml}$ injections in the submucosa at $1 \mathrm{~cm}$ from the lesion. ${ }^{28}$ If we injected 1 or 2 points, we could have had invisible cases. Actually, India ink or SPOT (GI supply, Camp Hill, PA, USA) are currently used to inject circumferential sites, in order to easily identify the dye on the mesenteric side of the bowel, in a retroperitoneal site, or under the greater omentum. ${ }^{29}$ Even though we had $100 \%$ visibility, we should attempt to make the tattooed area larger subsequently, so that we can clearly locate the lesion, even in special cases. This is because intraoperative bleeding can make the tattooed lesion blurred. A study introduced another unclear case with coagulopathy like in liver cirrhosis or thrombocytopenia, which used $6 \sim 12 \mathrm{ml}$ of autologous blood. ${ }^{14}$ Referring to these cases, we can attempt using total blood of "more than $12 \mathrm{ml}$ " in the next study to make a larger tattooed area, especially in a specific location or situation.

This study has several limitations. First, it is a retrospective 
study comprising a small sample size that is conducted in a single institution. Considering that this study included only 11 patients, several conclusions cannot be drawn from this study. However, considering the safety and feasibility of this study, conducting large-scale prospective studies are considerable. Second, because the tattooing case is selected based on the surgeon's preference, a selection bias may occur. Third, the surgeon already knows the location of the target lesion before surgery, subsequently starts performing the surgery, and spends a significant amount of time searching for the lesion, which can lead to high visibility called introduce bias. This can be overcome by conducting a prospective study that compares colonoscopic tattooing using India ink with other methods. Fourth, it was impossible to estimate the visibility time of a tattoo by performing surgery within at least 73 hours after tattooing. According to Kim et al., ${ }^{17}$ visibility was confirmed until 5 days, but no other studies have been conducted to assess visibility.

Despite these limitations, the result was valuable because we found that preoperative autologous blood tattooing is a very useful and safe technique. It has high visibility, no localization errors, and no complications. This method does not require additional agents or facilities. To have standard guidelines for using the autologous blood tattooing technique, large scale studies will be required.

\section{ORCID}

Ui Do Yeo, https://orcid.org/0000-0002-0206-8637

Nak Song Sung, https://orcid.org/0000-0002-7549-3829

Seung Jae Roh, https://orcid.org/0000-0002-3232-2798

Won Jun Choi, https://orcid.org/0000-0003-0278-4024

Kyung Ho Song, https://orcid.org/0000-0001-6661-3879

In Seok Choi, https://orcid.org/0000-0002-9656-3697

Dae Sung Yoon, https://orcid.org/0000-0002-6447-2862

Sang Eok Lee, https://orcid.org/0000-0002-9956-7693

Ju Ik Moon, https://orcid.org/0000-0002-8120-5854

Seong Uk Kwon, https://orcid.org/0000-0003-3167-7527

In Eui Bae, https://orcid.org/0000-0002-9220-8815

Seung Jae Lee, https://orcid.org/0000-0002-3302-6624

\section{AUTHORS' CONTRIBUTIONS}

Conceptualization: Nak Song Sung. Formal analyasis: Ui Do Yeo and Seung Jae Roh. Methodology: Kyung Ho Song and Nak Song Sung. Writing-original draft: Ui Do Yeo. Writing review and editing: Seung Jae Roh, Nak Song Sung, Won Jun Choi, In Seok Choi, Dae Sung Yoon, Sang Eok Lee, Ju Ik Moon, Seong Uk Kwon, In Eui Bae and Seung Jae Lee.

\section{CONFLICT OF INTEREST}

None.

\section{FUNDING}

None.

\section{ACKNOWLEDGMENTS}

We thank KH Song (colonoscopist) for the endoscopic tattooing procedure.

\section{REFERENCES}

1) Jayne DG, Thorpe HC, Copeland J, Quirke P, Brown JM, Guillou PJ. Five-year follow-up of the Medical Research Council CLASICC trial of laparoscopically assisted versus open surgery for colorectal cancer. Br J Surg 2010;97:1638-1645.

2) Nelson H, Sargent DJ, Wieand HS, et al. A comparison of laparoscopically assisted and open colectomy for colon cancer. N Engl J Med 2004;350:2050-2059.

3) Simunovic M, Baxter NN, Sutradhar R, Liu N, Cadeddu M, Urbach D. Uptake and patient outcomes of laparoscopic colon and rectal cancer surgery in a publicly funded system and following financial incentives. Ann Surg Oncol 2013;20:3740-3746.

4) Piscatelli N, Hyman N, Osler T. Localizing colorectal cancer by colonoscopy. Arch Surg 2005;140:932-935.

5) Saleh F, Abbasi TA, Cleghorn M, et al. Preoperative endoscopy localization error rate in patients with colorectal cancer. Surg Endosc 2015;29:2569-2575.

6) Park JW, Sohn DK, Hong CW, et al. The usefulness of preoperative colonoscopic tattooing using a saline test injection method with prepackaged sterile India ink for localization in laparoscopic colorectal surgery. Surg Endosc 2008;22:501-505.

7) Beretvas RI, Ponsky J. Endoscopic marking: an adjunct to laparoscopic gastrointestinal surgery. Surg Endosc 2001;15:1202-1203.

8) Tatsuno B, Murariu D, Bergmann L, Lorenzo CS, Bueno RS. Novel technique for preoperative localization of colorectal tumors for laparoscopic resection. Surg Laparosc Endosc Percutan Tech 2012;22: e281-283.

9) Cho YB, Lee WY, Yun HR, Lee WS, Yun SH, Chun HK. Tumor localization for laparoscopic colorectal surgery. World J Surg 2007;31: 1491-1495.

10) Kim SH, Milsom JW, Church JM, et al. Perioperative tumor localization for laparoscopic colorectal surgery. Surg Endosc 1997;11:10131016.

11) Acuna SA, Elmi M, Shah PS, Coburn NG, Quereshy FA. Preoperative localization of colorectal cancer: a systematic review and metaanalysis. Surg Endosc 2017;31:2366-2379. 
12) Lee SH, Kim DY, Oh SY, Lee KJ, Suh KW. Preoperative Localization of Early Colorectal Cancer or a Malignant Polyp by Using the Patient's Own Blood. Ann Coloproctol 2014;30:115-117.

13) Blouhos K, Boulas KA, Paraskeva A, et al. Preoperative endoscopic tattooing for colonic polyp localization: From blue to black. Clin Case Rep 2019;7:2258-2259.

14) Kim EJ, Chung JW, Kim SY, et al. Autologous blood, a novel agent for preoperative colonic localization: a safety and efficacy comparison study. Surg Endosc 2019;33:1080-1086.

15) Warnick P, Chopra SS, Raubach M, Kneif S, Hünerbein M. Intraoperative localization of occult colorectal tumors during laparoscopic surgery by magnetic ring markers-a pilot study. Int J Colorectal Dis 2013;28:795-800.

16) Frager DH, Frager JD, Wolf EL, Beneventano TC. Problems in the colonoscopic localization of tumors: continued value of the barium enema. Gastrointest Radiol 1987;12:343-346.

17) Gianom D, Hollinger A, Wirth HP. [Intestinal perforation after preoperative colonic tattooing with India ink]. Swiss Surg 2003;9:307310.

18) Park SI, Genta RS, Romeo DP, Weesner RE. Colonic abscess and focal peritonitis secondary to india ink tattooing of the colon. Gastrointest Endosc 1991;37:68-71.

19) Yano H, Okada K, Monden T. Adhesion ileus caused by tattoomarking: unusual complication after laparoscopic surgery for early colorectal cancer. Dis Colon Rectum 2003;46:987.

20) Bahadursingh AM, Driver M, Koenig CL, Longo WE. Inadvertent transmural India ink tattooing simulating intestinal infarction. Am J Surg 2003;185:88-89.

21) Nizam R, Siddiqi N, Landas SK, Kaplan DS, Holtzapple PG. Colonic tattooing with India ink: benefits, risks, and alternatives. Am J Gastroenterol 1996;91:1804-1808.

22) Kethu SR, Banerjee S, Desilets D, et al. Endoscopic tattooing. Gastrointest Endosc 2010;72:681-685.

23) Miyoshi N, Ohue M, Noura S, et al. Surgical usefulness of indocyanine green as an alternative to India ink for endoscopic marking. Surg Endosc 2009;23:347-351.

24) Hammond DC, Lane FR, Mackeigan JM, Passinault WJ. Endoscopic tattooing of the colon: clinical experience. Am Surg 1993;59:205-210.

25) Price N, Gottfried MR, Clary E, et al. Safety and efficacy of India ink and indocyanine green as colonic tattooing agents. Gastrointest Endosc 2000;51:438-442.

26) Lee SJ, Sohn DK, Han KS, et al. Preoperative Tattooing Using Indocyanine Green in Laparoscopic Colorectal Surgery. Ann Coloproctol 2018;34:206-211.

27) Satoyoshi T, Okita K, Ishii M, et al. Timing of indocyanine green injection prior to laparoscopic colorectal surgery for tumor localization: a prospective case series. Surg Endosc 2020 Feb 18 [Epub]. https://doi. org/10.1007/s00464-020-07443-5.

28) Botoman VA, Pietro M, Thirlby RC. Localization of colonic lesions with endoscopic tattoo. Dis Colon Rectum 1994;37:775-776.

29) Kalady MF. Surgeon involvement in preoperative colorectal tumor localization. World J Surg 2010;34:1592-1593. 